\title{
Coastal Objects: Mangrove Area Extraction Using Remote Sensing and Aerial LiDAR Data in Roxas, Oriental Mindoro
}

\author{
Donald A. Luna ${ }^{1, *}$, Davies V. Ocampo ${ }^{1}$, Sarena Grace L. Quiñones ${ }^{1}$, Efren C. Rivera ${ }^{1}$, \\ Charmina G. Sejalbo ${ }^{1}$, Precious R. Zara ${ }^{1}$, Kenneth Bernard M. Hizon ${ }^{1}$, \\ Jovy Anne V. Delos Reyes ${ }^{1}$, Victor S. Ticzon ${ }^{2}$, Damasa M. Macandog ${ }^{2}$ \\ ${ }^{1}$ Phil-LiDAR 2 UPLB, University of the Philippines Los Baños, Philippines \\ ${ }^{2}$ Institute of Biological Sciences, College of Arts and Sciences, University of the Philippines Los Baños, Philippines
}

Copyright $\bigcirc 2017$ by authors, all rights reserved. Authors agree that this article remains permanently open access under the terms of the Creative Commons Attribution License 4.0 International License

\begin{abstract}
The Phil-LiDAR 2 program aims to extract the natural resources of the Philippines from the available two points per square meter LiDAR data. Mangroves, being coastal resources, were one of the foci of this program under the Aquatic Resources Extraction from LiDAR Surveys (CoastMap). The object-based image analysis (OBIA) approach, and support vector machine (SVM) algorithm were utilized to classify three major classes from the LiDAR data, namely: mangrove, other vegetation, and non-vegetation. Object feature values used in the classification include the mean, standard deviation, mode, and texture values from the generated LiDAR derivatives. These derivatives include the Digital Surface Model (DSM), Digital Terrain Model (DTM), Canopy Height Model (CHM), Intensity, Number of Returns, Normalized DSM (NDSM), Slope, and Slope of Slope. Moreover, field data collection and validation provided key references in the supervised SVM classification and contextual editing of the extracted mangrove areas. From the implemented classification, an overall accuracy of above $90 \%$ was achieved. Focusing with the final classified mangrove coverage, management of the mangrove resources can be made proper and efficient. Furthermore, high resolution or detailed spatial information can support programs like Reducing Emissions from Deforestation and forest Degradation Plus (REDD+) and biodiversity studies.
\end{abstract}

Keywords LiDAR, Mangrove, Resource Extraction, OBIA, SVM

\section{Introduction}

Mangrove ecosystems are formed along the tropical and sub-tropical coasts. It also extends in the brackish water along the streams and rivers [1]. It is also known as the sea rainforest where it usually grows in tropical countries like the Philippines.

Generally, the mangrove ecosystem is important in the coastal, marine, and terrestrial ecosystem. Mangroves are ecotones linking the marine and terrestrial ecosystems. Specifically, mangrove ecosystem serves as a home to monitor lizards, fishing cats, monkeys, manatees, sea turtles, and mud-skipper fish. It also serves as nesting and migratory sites for several species of birds and nursery ground for juvenile fish, shrimps, crabs, and mollusks. In terms of coastal area protection, the ecosystem can be used for water retention, nutrient recycling, shoreline and riverbanks protection from erosion by sediment stabilization and absorption of pollutants, and protection from storm surges [2-4]. Aside from the ecological benefits it can provide, there are also economic benefits from products such as wood and fish.

However, despite of these benefits, there is a continuous decrease in mangrove resources around the world [5]. In Southeast Asia, this decrease has also been observed and accounted from key factors such as wood extraction, area conversion to agriculture and aquaculture, tin mining, and coastal urbanization $[6,7]$.

In the Philippines, it was recorded that there are around 46 species in the country out of the 70 species of mangroves around the world. The mangrove forest cover in the country was estimated to be $400,000-500,000$ ha in 1918 [8]. However, it has decreased through the years because of direct and indirect threats to the ecosystem. Then, in 2000, the remaining mangrove areas dropped to $130,000 \mathrm{ha}$. [9].

With the decrease in mangrove forest cover, the ecological services provided also tend to decrease. Thus, at present, there is a need for proper and efficient mangrove resources 
management. One way to efficiently and properly manage the mangrove resources is through mapping the resources, wherein larger areas can be covered with lesser cost and time with an acceptable degree of acceptance or error.

Natural resources mapping is now being done through earth observation methods. Traditional mapping of resources are costly, only cover small area, and difficult to conduct [10]. Thus, new technology such as remote sensing and Geographic Information System (GIS) must be used to efficiently map the resources. Remote sensing is defined as a method of collecting data of an object from the measurement made at a distance [11]. It is being popularly used in gathering information from areas which are often unreachable because of logistics issue. Remote sensing has been used in research areas such as land use/cover changes or mapping in wetland regions, carbon cycle and climate warming in wetland environments, release of carbon by peatland fires, and hydrology processes in wetlands [16]. Moreover, through this method large areas can be mapped at a short time and at a lower scale.

Mangrove resources can be mapped through remote sensing. Previous studies conducted have showed that mangroves extraction using remote sensing classification has accuracy from $75 \%$ to $90 \%$ [12]. Remote sensing techniques include the use of aerial photographs, satellite images, radar, and LiDAR technology. Light Detection and Ranging or LiDAR, specifically aerial LiDAR, is a technology that can provide a higher resolution image of an area as compared to MODIS, Landsat, and Sentinel satellite images. It uses pulse of light energy in measuring the distance between sensor and target object [16]. When these pulses are emitted these will be reflected by the ground feature and the precise time will be recorded [13]. LiDAR can provide spatial data which can be used in various applications such as flood modelling, hazard assessment, urban development, site design engineering, and natural resource management among others. Also, this is popularly used in updating topographic data of an area [14]. LiDAR data derives accurate ground elevations, sea level rise, and produces accurate results when it comes to the elevation and structure of landscapes [16]. Data derived from LiDAR are also flexible in scale and format such that it can be analyzed as a collection of points, as a derived raster layer, or as a series of raster layers [19]. Zhang $[16,17]$ used LiDAR in a study that derived the elevation difference between the ground surface and canopy, and identified gaps in the mangrove forest. A study by Boehm et al $[16,18]$ also used LiDAR datasets from August 2007 to August 2011 to monitor peat swamp forest changes, and measure the height of forest in comparison to field survey results.

Geographic Information System (GIS) is a tool for interpreting the remotely-sensed data. It can provide various spatial characteristics through the digital layers derived from the data [11]. The combination of remote sensing and GIS is helpful particularly in resource management because managers and other concerned people can refer to spatial data to make effective laws in managing and conserving the resources.

One method to classify remotely sensed data is the Object-based Image Analysis (OBIA). Studies showed that spatial information used in OBIA improves the accuracy of classification [12]. Support Vector Machine or SVM is also a helpful machine learning technique for multispectral classifications that can be applied to OBIA. Previous studies conducted using Support Vector Machine (SVM), in combination with OBIA, were able to provide satisfactory results for mapping land cover, particularly mangrove resources. The segmentation methods done were effective in differentiating the spectral difference among various land cover features. Moreover, several parameters were used to make the extraction more effective. Some of the parameters used in extracting mangroves are scale, shape, compactness, texture, and relation with other objects $[12,15]$.

This study used the aerial LiDAR technology in extracting the mangrove resources in Roxas, Oriental Mindoro, Philippines. It aimed to provide the local government unit of Roxas with a more detailed mangrove map that can be used in their resource management plans. The OBIA approach and SVM classification algorithm were implemented using three classes namely, mangrove, non-vegetation, and other vegetation. The parameters used were object texture, basic metrics, and distance to water from the image.

\section{Materials and Methods}

The study was conducted along the shore of the municipality of Roxas in the province of Oriental Mindoro, Philippines (Figure 1). 


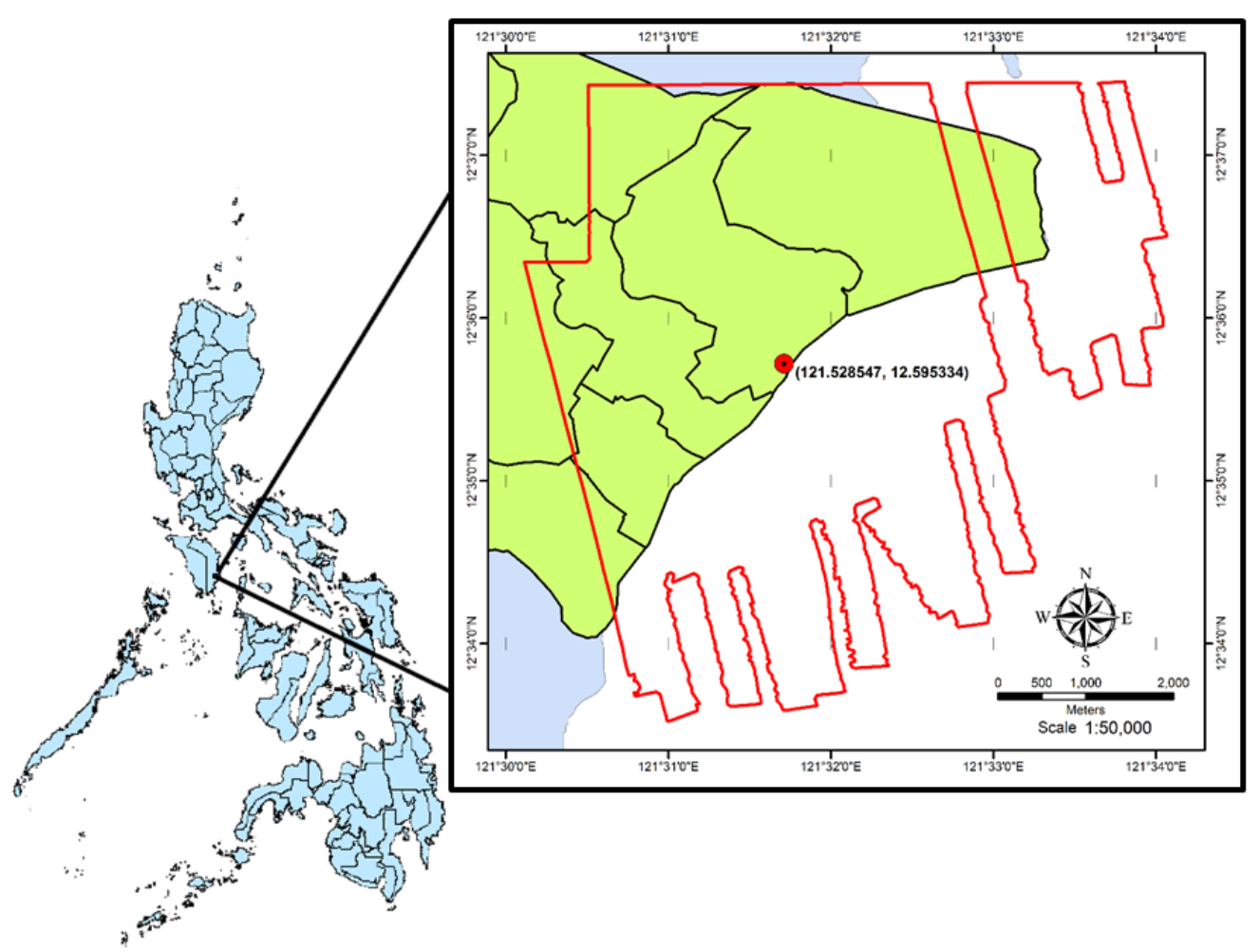

Figure 1. Location of the study site at Roxas, Oriental Mindoro, Philippines and the flight plan during LiDAR data acquisition

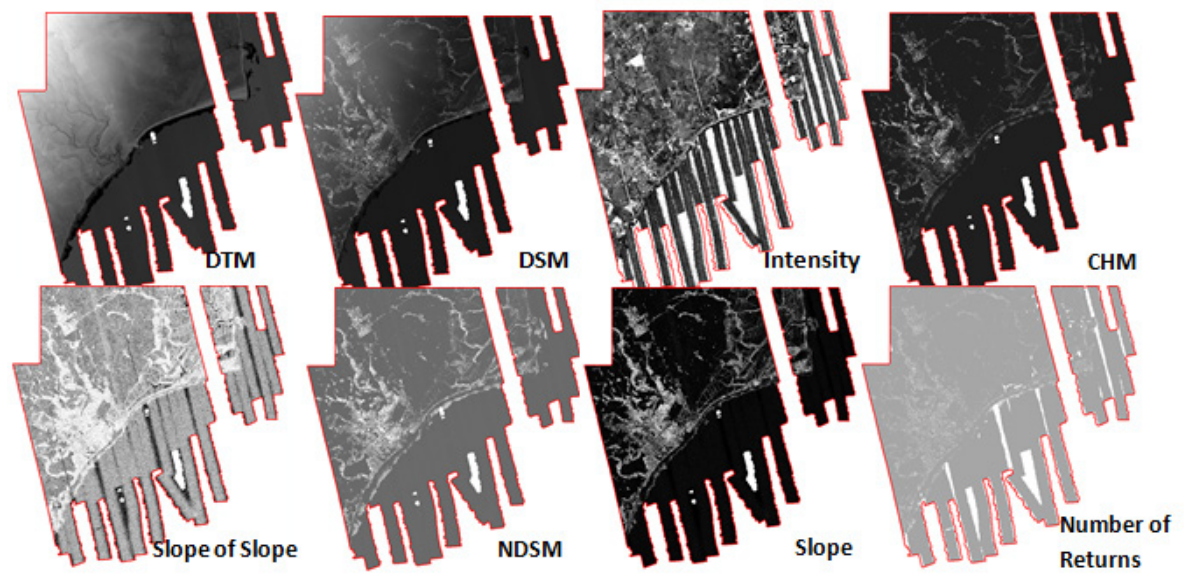

Figure 2. Input LiDAR derivatives for the mangrove area extraction

Processed LiDAR coverage has an area of 3,306.9501 hectare (ha) or 33.0695 square meter $\left(\mathrm{m}^{2}\right)$. This includes both land and water resources. Raw LiDAR data was collected under the University of the Philippines DREAM Program to be used for detailed flood modelling. This LiDAR data was collected using an ALTM Aquarius Optech Inc. sensor, which has 4 range capture measurements and $33,50.70 \mathrm{kHz}$ of laser pulse repetition rate. Furthermore, collected LiDAR data are within the $50 \mathrm{~cm}$ and $20 \mathrm{~cm}$ horizontal and vertical accuracies standard set by the UP DREAM Program, respectively. Having a two points per square meter resolution, additional utilization of the LiDAR data was given to the Phil-LiDAR 2 Program for detailed resource extraction. Both were nationwide Programs having about 15 State Universities and Colleges and High Education Institutes as partners. One of which was Phil-LiDAR 2 UPLB Project, which was tasked to map the MIMAROPA Region, and Laguna Province of the Philippines.

\subsection{LiDAR Derivative Inputs}

Extraction process was limited to the use of only LiDAR data. Initial derivatives, namely, Digital Surface Model (DSM), Digital Terrain Model (DTM), Canopy Height Model (CHM), Intensity, and Number of Returns having a 0.5 meter raster cell size were generated using LAStools. While the additional derivatives, namely, Normalized Digital Surface Model (NDSM), Slope, and Slope of Slope were created using raster capable processing software. 
DTM represents the bare earth surface, while DSM is the bare earth together with all other features like crops, trees, buildings, and roads, etc. Intensity, on the other hand, shows the average measure of reflected laser pulse from the ground back to the sensor. Following the method from LAStools, CHM represents solid tree canopies, buildings and other non-ground features in a flat terrain. Slope was generated from the DSM layer and emphasizes the edges of existing features. While Slope of slope was generated from the Slope existing slope derivative and highlights further the edges of features.

NDSM is the result of DTM removed from DSM (NDSM = DSM - DTM), where the terrain was flattened to capture the height of given features like buildings and trees. Lastly, the Number of Returns is the number of layers that the laser pulse hit during LiDAR data collection. Flat surfaces tend to have a smaller number of returns value as compared to vegetation or irregular surfaces.

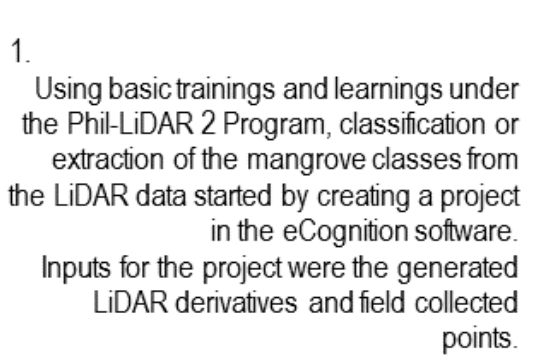

4.

The default values of 0.1 and 0.5 for Shape and Compactness, respectively, and a Scale parameter of 10 were used for the multiresolution segmentation. Hundreds and more "objects" are created after this process

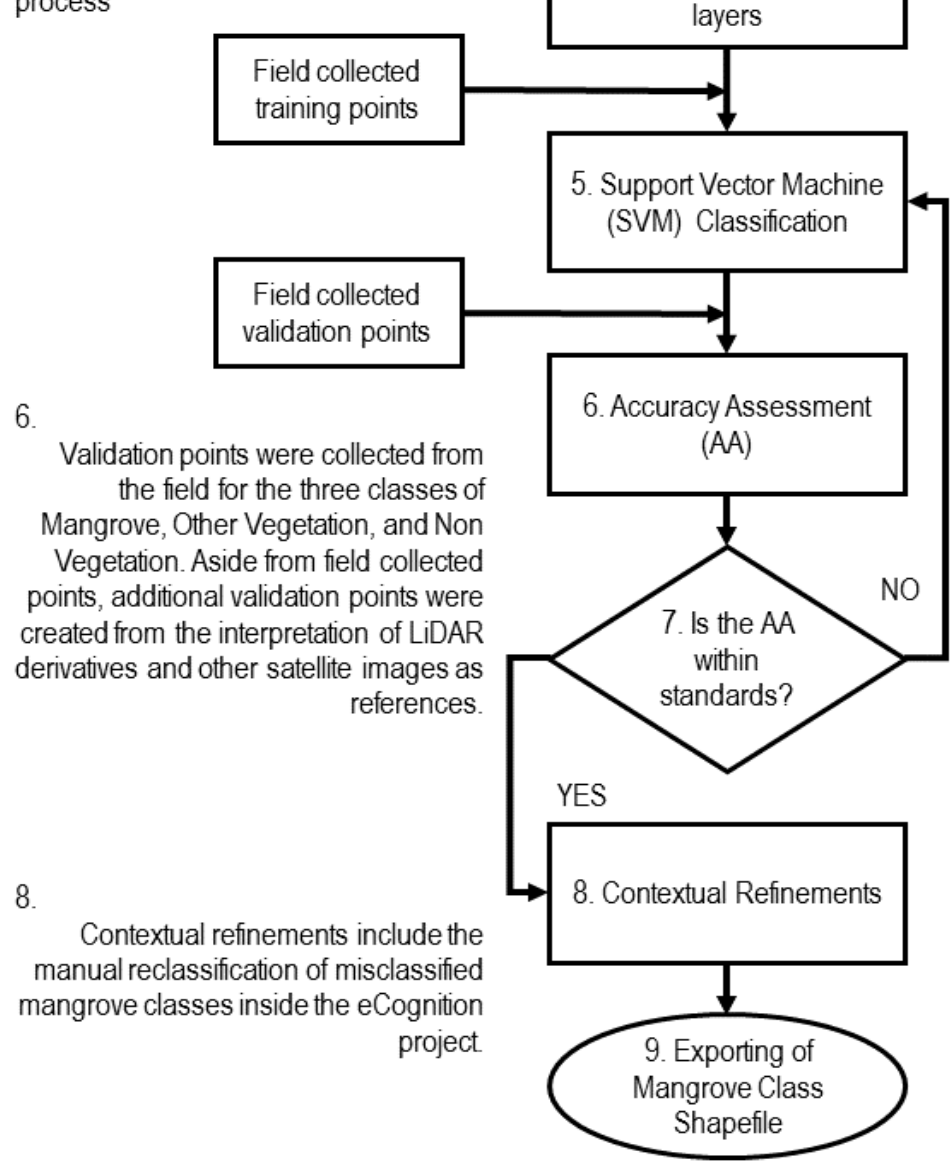

2-3.

Pixel values were inspected and utilized in implementing a multi-threshold segmentation to extract of the Non-

2. Separation of No Data, Water and Land Classes ground classes from the Land Classes. It is in the Non-ground classes were classification were performed.

\section{5.} Available in the eCognition project is the SVM algorithm. With SVM, a supervised classification was implemented using field collected training points and object feature values of the LiDAR derivatives. Objects were classified and used as samples for the SVM process. Additional training points were created from the interpretation of LiDAR derivatives and other satellite images as references.

7.

The Phil-LiDAR 2 Program's CoastMap requireS that the overall classification accuracy is above $90 \%$ while per class accuracy is above $80 \%$.

Once conditions are met, the process moves to the refinement of the mangrove class. Otherwise, the process is reviewed, revised and repeated at the SVM classification level.

\section{9.}

After finalization, only the mangrove class is exported as shapefile. 


\subsection{Classification Workflow}

Figure 3 shows the basic workflow implemented in the classification and extraction of the mangroves. In OBIA, instead of pixels, objects were used and classified. Values of these objects differ depending on the portion or values LiDAR derivatives that the object covers. Basic statistics like mean, standard deviations, mode, and texture values were among the inputs for classification. Being objects, geometry values like area and the distance of these objects from certain classes were utilized. However, there were no attempt to identify key features or values that can efficiently separate the three classes of mangrove, Other Vegetation, and Non Vegetation.

Training and validation points were scattered along the processed image. The number of the training points per class is as follows: Mangrove -45 , Other Vegetation -70 , and Non Vegetation - 35. While the validation points were 15 for each classes. It was consciously attempted that no training and validation points overlap or are near each other. Contextual editing was limited to misclassified Mangrove and Other Vegetation classes. One possible reason is that only LiDAR data was used in the classification, wherein height and texture values were the basis for classification.

\section{Results and Conclusions}

From the total $3,306.95$ ha of LiDAR data coverage, about 90.80 ha was computed from the exported mangrove shapefile. An overall accuracy of above $90 \%$ (Figure 4) was obtained by implementing an SVM classification under an OBIA approach for the three classes of Mangrove, Other Vegetation, and Non Vegetation. The DTM generated from LiDAR was very useful in contextual editing of the classification since mangroves in Roxas were located mostly in low elevation areas where estuaries were located.

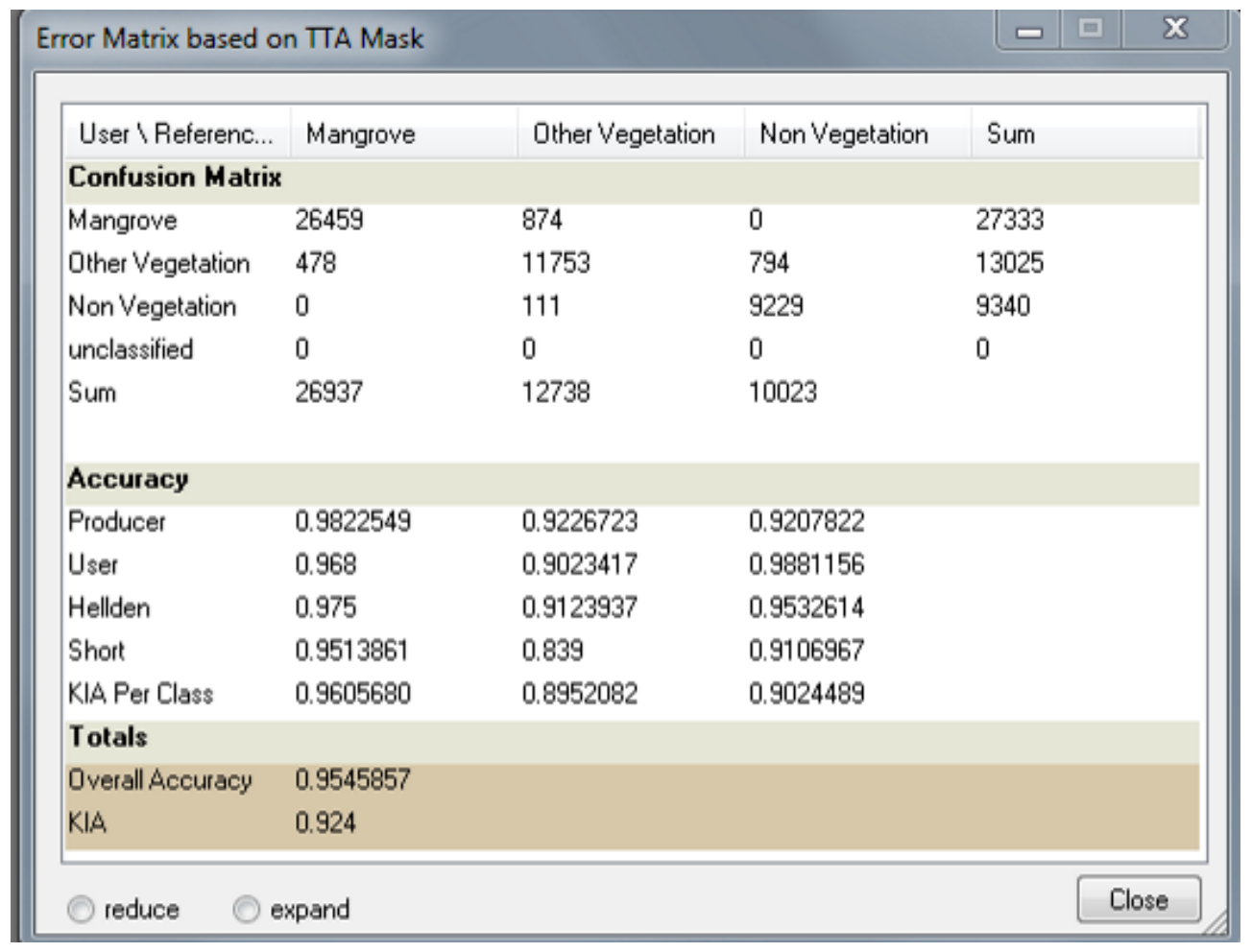

Figure 4. Accuracy Assessment Result 


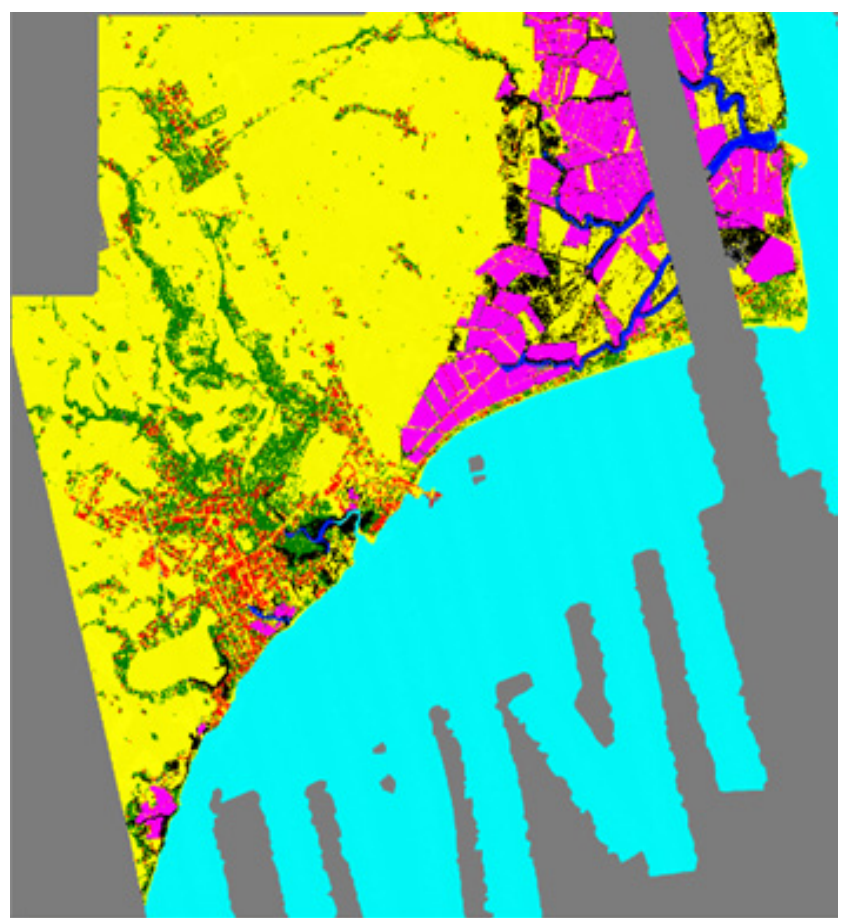

Figure 5. Final Mangrove Map of Roxas, Oriental Mindoro (RED: Non-Vegetation, GREEN: Other Vegetation, BLACK: Mangrove, YELLOW: Ground, and FUCHSIA: Aquaculture)

Figure 5 shows the final mangrove map of Roxas, Oriental Mindoro. In conclusion, the high resolution presented by the LiDAR data was able to extract the mangrove areas of Roxas. However, a number of misclassifications were encountered and consequently needed refinements since features were limited to those related to height values.

With the final extracted mangrove coverage, management of the mangrove resources can now be proper and efficient. Furthermore, this kind of detail in spatial information can support programs like the Reducing Emissions from Deforestation and forest Degradation Plus (REDD+) and even biodiversity studies. With the results of this study, the Municipality of Roxas, Oriental Mindoro can now be provided with an updated and more detailed mangrove map that can be used for their management. At the same time, other local government units covered by LiDAR data can also be provided with the same detailed resource maps. Future and in-depth uses are for detailed carbon stock calculations, tree counting workflow using remote sensing and LiDAR in the Philippines.

\section{Acknowledgements}

The researchers would like to thank the following: Department of Science and Technology Grants-in-Aid as the funding agency; Philippine Council for Industry, Energy and Emerging Technology Research and Development (PCIEERD) as monitoring agency, University of the Philippines DREAM Program, Phil-LiDAR 2 Program's
Philippine Agriculture Resource and Aquatic Resources Mapping Components, Provincial Agriculture Office-Oriental Mindoro, Municipal Agriculture OfficeRoxas, Malampaya Foundation, Inc., and DAAD Bioluz Project Department of Animal Ecology, Philipps-University Marburg.

\section{REFERENCES}

[1] Melana, D.M., J. Atchue III, C.E. Yao, R. Edwards, E.E. Melana and H.I. Gonzales. 2000. Mangrove Management Handbook. Department of Environment and Natural Resources, Manila, Philippines through the Coastal Resource Management Project, Cebu City, Philippines. 96 p.

[2] White, A. T. and A. C. Trinidad. 1998. The values of Philippines coastal resources: why protection and management are critical. Coastal Resource Management Project, Cebu City, Philippines, $96 \mathrm{p}$

[3] Dieta, R.E., \& Arboleda, F.C. 2004. The use of mangroves for aquaculture: Philippines. In: Promotion of mangrove-friendly shrimp aquaculture in Southeast Asia (pp. 151- 159). Tigbauan, Iloilo, Philippines: Aquaculture Department, Southeast Asian Fisheries Development Center.

[4] Lugo, A.E., Snedaker, S.C., 1974. The ecology of mangroves. Annual Review of Ecology \& Systematics 5, 39-64.

[5] Field, C. D. (1999). Rehabilitation of Mangrove Ecosystems: An Overview. Elsevier Science Ltd. 384

[6] Ong, J. E. (1995). The ecology of mangrove conservation and management. Hydrobiologia. 295, 341-343

[7] Macintosh, D. J. (1996). Mangroves and Costal Aquaculture: doing something positive for the environment. Aquaculture Asia I (2). 3-8

[8] Brown, W. H. and A. F. Fischer. 1918. Philippine mangrove swamps, Bureau of Forestry Bull. No. 17. Department of Agriculture and Natural Resources, Bureau of Printing, Manila.

[9] Aizpuru, M., Achard, F., and Blasco, F. 2000. Global Assessment of Cover Change of the Mangrove Forests using satellite imagery at medium to high resolution. In EEC Research project n 15017-1999-05 FIED ISP FR - Joint Research center, Ispra.

[10] Tuhldahl, H. M. and S. A. Wikström. 2012. Classification of aquatic macrovegetation and substrates with airborne lidar. Remote Sensing of Environment 121: 347-357.

[11] Dahdouh-Guebas, F., 2001. The use of Remote Sensing and GIS in Sustainable Management of Tropical Coastal Ecosystems. Retrieved from http://link.springer.com/article/ 10.1023/ A: 1020887204285.

[12] Heumannm B., 2011. An Object Based Classification of Mangroves Using a Hybrid Decision Tree Support Vector Machine Approach, www.mdpi.com/journal/remotesensing

[13] Denny, K., n.d. LiDAR: Derivatives \& Applications in a PowerPoint presentation [PowerPoint slides]. Retrieved from 
http://www.adeca.alabama.gov/Divisions/owr/floodplain/NFI P/LiDAR \%20-\%20Derivatives\%20and\%20Applications.pdf.

[14] Johansen K., S. Phinn and C. Witte. 2010. Mapping of riparian zone attributes using discrete return LiDAR, QuickBird and SPOT-5 imagery: Assessing accuracy and costs. Remote Sensing of Environment 114:2679-2691.

[15] Conchedda, G., Laurent D., Philippe M., 2008. Object-based Monitoring of Land Cover Changes in Mangrove Ecosystems of Senegal, 2008 International Society for Photogrammetry and Remote Sensing, Inc., Elsevier B.V http://www. sciencedirect.com/science/article/pii/S09242716 08000294

[16] Guo, M., Li, J., Sheng, C., Xu, J. \& Wu, L. (2017). A Review of Wetland Remote Sensing Sensors (Basel, Switzerland)
$17(4)$.

[17] Zhang, K. (2011). Analysis of non-linear inundation from sea-level rise using LiDAR data: A case study for South Florida. Climate Change, 106, 537-565.

[18] Boehm, H.D.V., Liesenberg, V., Limin, S.H. (2013). Multi-temporal airborne LiDAR-survey and field measurements of tropical peat swamp forest to monitor changes. IEEE J. Sel. Top. Appl. Earth Obs. Remote Sense, 6, 1524-1530.

[19] Blanchard, S.D., jakubowski, M.K., Kelly, M. (2011). Object-Based Image Analysis of Downed Logs in Disturbed Forested Landscapes Using Lidar, Remote Sensing. ISSN 2072-4292, www.mdpi.com/journal/remotesensing 